\title{
Numerical simulation of beam-to-column joints with flange cleats
}

\author{
Agnieszka Jabłońska-Krysiewicz;, and Jakub Gołowczyc (student)
}

Faculty of Civil and Environmental Engineering, Bialystok University of Technology, 15-351

Białystok, Poland

\begin{abstract}
Although the effect of semi-rigid steel beam-to-column connections on the behaviour of steel frames and their substantial economic benefits are recognized nowadays, many structural analyses still consider connections as either fixed or pinned. For that reasons, there is need to be able the generate moment-rotation responses of semi-rigid connections that can be used for analysis and design proposes. Characteristic of the joints can be found using FEM models. The objective of the analysis was to find moment-rotation curves for beam-to-column joints with flange cleats and compare them to curves obtained from experimental studies. Numerical elastic-plastic 3D finite models was performed in order to establish a numerical analysis method for evaluating deformation of connections. For all joints there were obtained the FE results lightly underestimates results achieved from experiments. Some differences in the initial value of stiffness and resistances indicate the need for further work on improving FEM models. The inclusion of dimensional deviations of the IPE nad HEB sections, variability in the values of the prestressing forces of the bolts and the not centric positions of the bolts in the holes in the FEM model may contribute to increasing the degree of compliance of the results from experimental and numerical analyzes.
\end{abstract}

\section{Introduction}

Cost optimization is one of the most important items in steel construction in order to be competitive in the market of buildings. The joints determine almost $50 \%$ of the total cost of steel structure. The cost of joints can decrease substantially if stiffeners between flanges can be avoided [1]. The distribution of forces and moments in the structure due to the loading is a result of the strength and stiffness distribution in the structure. So the structural characteristics of the joints such as stiffness, strength and rotation capacity, together with those of the structural components like beams and columns, produce these forces in the joints. This means that the choices made by the designer in designing the joints, including the connecting parts, are of direct influence on the level of forces and moments in these joints. In fact construction is joining components such as column and beams together while designing is making choices for components taking the structural properties such as strength and stiffness into account $[2,3]$.

\footnotetext{
* Corresponding author: a.krysiewicz@pb.edu.pl
} 
Existing design procedures for steel frames have been modified during the last three decades to incorporate the semi-rigid behavior of the connections into the frame design process. However, if one consider the large number of variables related to connection geometry, connection components, and constitutive relationships for their materials, the task of deriving simplified guidelines for the incorporation of semi-rigid behavior into design is a formidable analytical assignment. This task is further complicated by the need to treat the problem in three dimensions, to consider nonlinear geometric and material effects and to include the effects of initial imperfections and residual stresses. In spite of these difficulties and complexities, in the past two decades a large number of advanced FE studies have been conducted on connections to provide stiffness, strength and ductility estimates for a large variety of connection geometries $[4,5,6]$. These FE models have been used to develop moment-rotation curves, to verify design methodologies based on yield lines and other plastic design concepts, and to asseses local behavior in the connection components.

In general, these detailed studies have attempted to develop global connection behaviour responses, for example moment-rotation curves, that can be readily incorporated into modern structural analysis programs like ADINA, COSMOS, NASTRAN, ANSYS, and ABACUS.

The objective of the analysis was to find moment-rotation curves for beam-to-column joints with flange cleats using the FEM analysis and compare them to curves obtained from experimental studies.

\section{Description of the specimens}

The joint specimens for numerical investigations have the same material and geometrical properties like the experimental specimens tested by Skejic and others $[7,8]$. There were used hot rolled sections IPE200 as a beam, HEM400 as a column. Both of them there were designed from steel grade S460. This selection of the column beam and steel grade was carefully chosen since it was required that they remain undamaged during the testing. There were tested two types of specimens: beam-to-column joint with unstiffened flange cleats (Fig.1) and with stiffened flange cleats (Fig.2). The positions of unstiffened and stiffened angles which were placed on the top and bottom of the beam are varied. The flanges cleats were made of the angle profile 150x90x10, steel grade S235 JR and their length fitted the beam flange width equal to $200 \mathrm{~mm}$ (Fig.3).

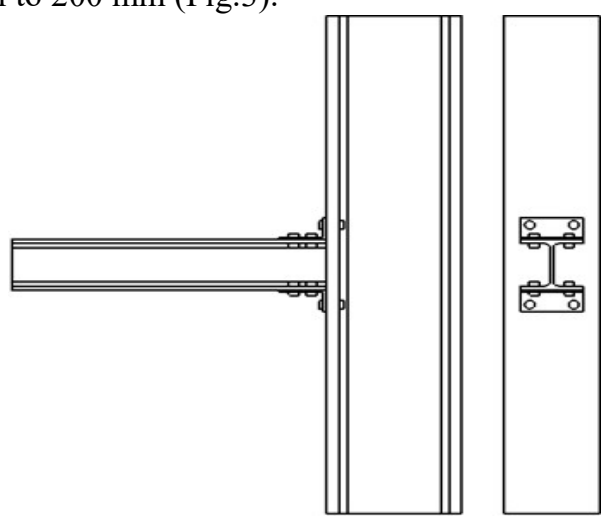

Fig. 1. Beam-to-column joint with unstiffened flange cleats-W-1. 


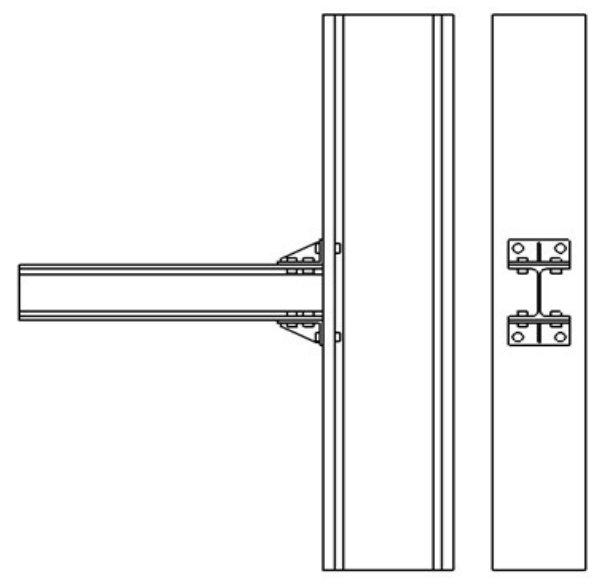

Fig. 2. Beam-to-column joint with stiffened flange cleats W-4.

The same bolts M16 grade 10.9 were used in both types of specimens. All bolts were tightened to $105 \mathrm{Nm}$, which corresponds the prestressing force of $26 \mathrm{kN}$ (app. $20 \%$ of the bolt tensile strength).

a)

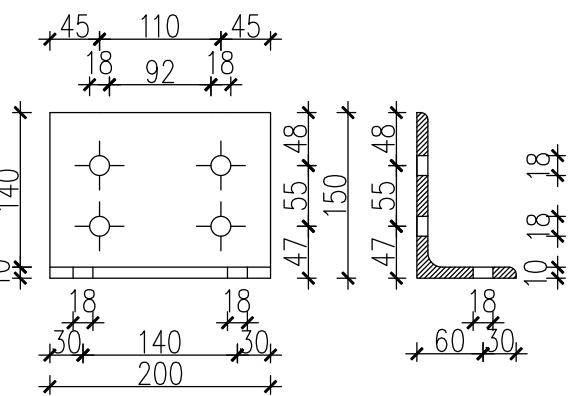

b)

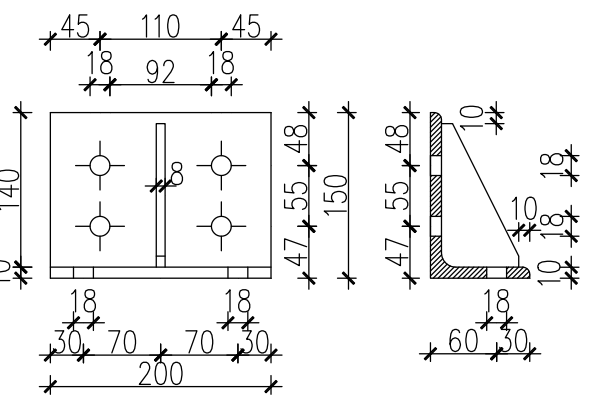

Fig. 3. The dimensions of angle cleat: a) without and b) with stiffener. [8]

It should be noted that the bolt spacing on the shorter and longer angle leg was the same. That means that the distance between the beam and the column flange in all joint specimens was $2 \mathrm{~mm}$.

Stiffeners were made with an $8 \mathrm{~mm}$ thick plate with steel grade S $235 \mathrm{JR}$. the nominal steel quality of the joint element and bolts was the same for all specimens [7].

During the experimental testing providing by Skejic and others [7,8] the loading was applied on the beam at position $834 \mathrm{~mm}$ from connection. In this way it was possible to test the flange cleat in tension (inducing bending in angle legs), i.e. to record the actual response of the component when the component functions as integral part of the joint.

\section{Finite element modelling}

\subsection{General}

The numerical tests were carried out by code ANSYS -Workbench version 14 [9]. Solid 186 elements were used to mesh the beam, column, cleats, stiffener and bolts. Contact surfaces between the flange of column and cleats, the bolt shanks and cleats and flange of column, 
and nuts and heads of bolts and flange of column and cleats are meshed by Conta174 elements. The description of these elements taken from ANSYS Manual [9] is listed in the next subsection. The coefficient of friction of 0.2 is employed for contact surfaces. The meshed FE models of connection, stiffened cleat and bolt are shown in Fig.4 and 5.

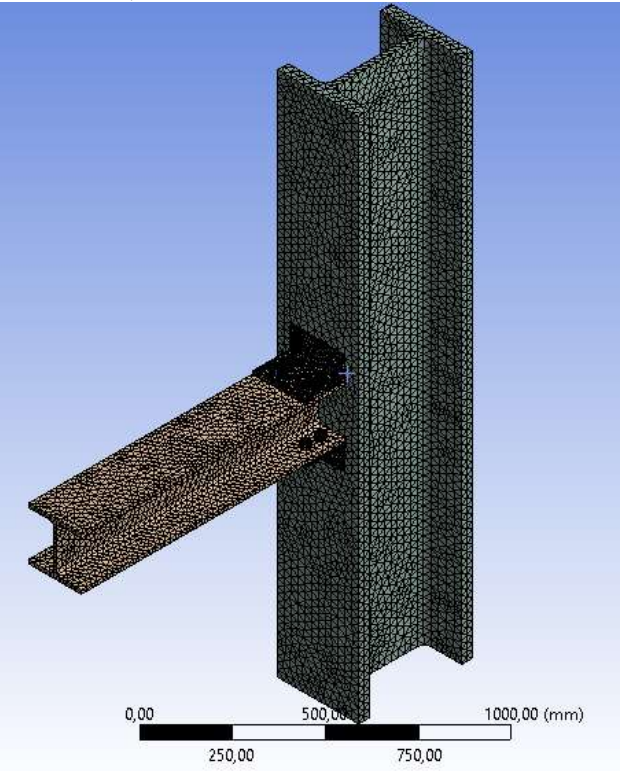

Fig. 4. Finite element models of beam-to-column joint with unstiffened flange cleats.

a)

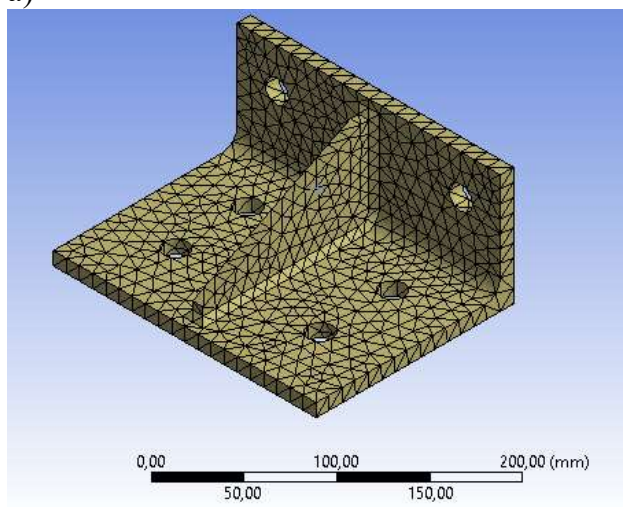

b)

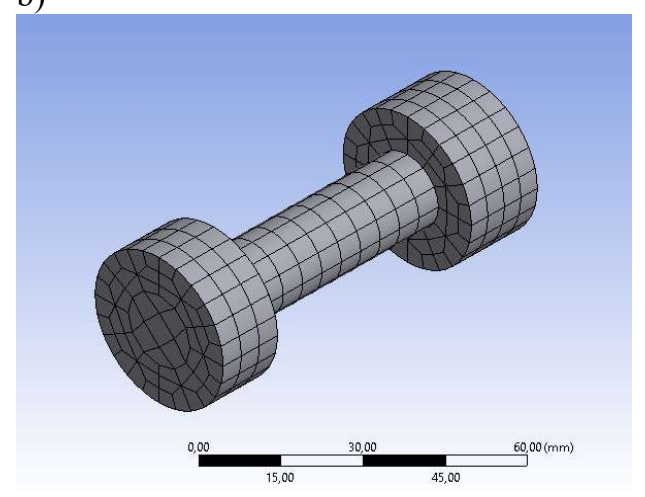

Fig. 5. Finite element models of : a) stiffened flange cleat and b) bolt.

Table 1 presents the number of nodes and elements for both finite element models of joint variants: stiffened and un-stiffened.

Table 1. The number of elements and nodes for finite elements models.

\begin{tabular}{|c|c|c|}
\hline $\begin{array}{c}\text { Type of } \\
\text { joint }\end{array}$ & $\begin{array}{c}\text { Number of } \\
\text { elements }\end{array}$ & $\begin{array}{c}\text { Number of } \\
\text { nodes }\end{array}$ \\
\hline Unsiffened & 101879 & 194528 \\
\hline Stiffened & 103307 & 197082 \\
\hline
\end{tabular}




\subsection{Element description}

Solid 186 is used for the 3-D modeling of solid structures. The element is defined by twenty nodes having three of freedom at each node: translation in the nodal $\mathrm{x}, \mathrm{y}$ and $\mathrm{z}$ directions. The element has plasticity, creep, swelling, stress stiffening, large deflection and large strain capabilities.

Conta174 is used to represent contact and sliding between 3-D "target" surfaces (Targe 170) and deformable surfaces, defined by this element. The element is applicable to 3D structural and coupled field contact analyses. This element is located on the surfaces of 3D solid elements. It has the same geometric characteristics as the solid element face with which it is connected. Contact occurs when element surface penetrates one of the target segment elements (Targe 170) on a specified target surface. Coulomb and shear stress friction is allowed.

\subsection{Material property}

The 3-D model uses the bilinear isotropic hardening option for plate elements of joints. The Huber- von Mises yield criteria was employed to define the plasticity. For this option is preferred for large strain analyses. The material behaviour is described by bilinear stressstrain curve. The initial slope of the curve is taken as the elastic modulus of the material. At the yield stress, the curve is continuous along the second slope defined by the tangent modulus. The tangent modulus is defined as about $0.1 \%$ of the initial modulus of elasticity. For bolts there are used linear model of material. The material property of plate components and bolts in joints are listed in Table.2.

Table.2. Material properties

\begin{tabular}{|c|c|c|c|}
\hline Elements & $\begin{array}{c}\text { Yield stress } \\
{[\mathbf{M P a}]}\end{array}$ & $\begin{array}{c}\text { Elastic } \\
\text { modulus } \\
{[\mathbf{G P a}]}\end{array}$ & $\begin{array}{c}\text { Tangent } \\
\text { modulus[MPa] }\end{array}$ \\
\hline Beam, column, & 460 & 210 & 540 \\
\hline $\begin{array}{c}\text { Flange cleats } \\
\text { and stiffeners }\end{array}$ & 235 & 210 & 360 \\
\hline Bolts & 900 & 210 & - \\
\hline
\end{tabular}

\section{Comparison of numerical simulation results with experiments}

The numerical analyses were made in two steps. In first step the prestressing force was introduced into bolts, in second one the force were applied to free end of beam section in 10 steps of load to keep respectively value of bending moment in each connection. The moment-rotation curves achieved from FE models calculations were depicted on Fig.6. 


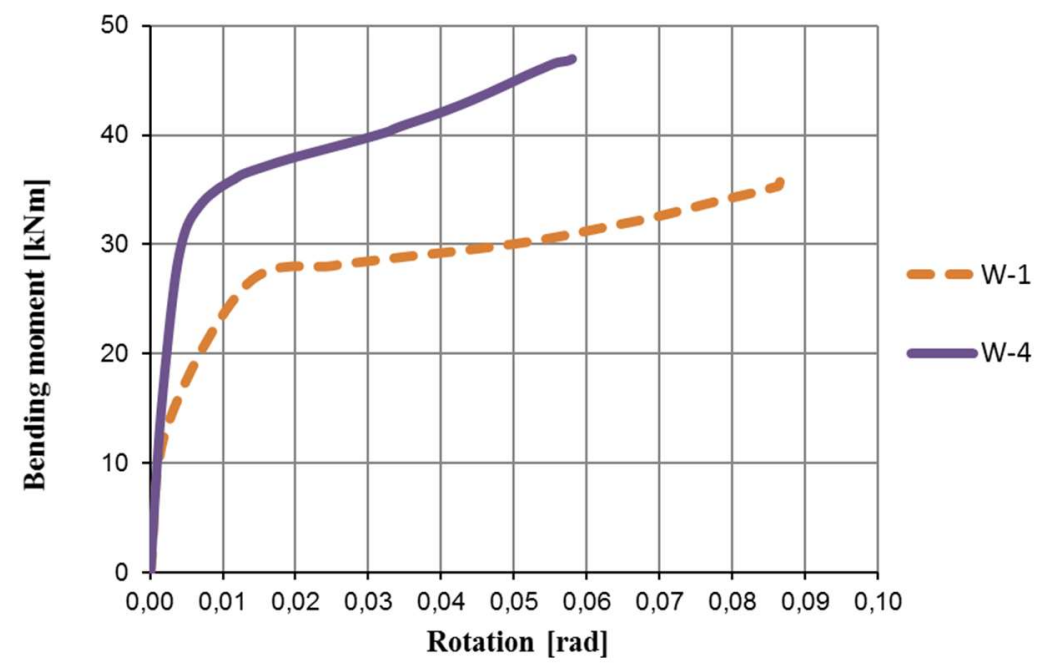

Fig. 6. Moment-rotation curves obtained from numerical analysis.

In connection $\mathrm{W}-1$, in which unstiffened angles are used, a higher deformability of the connection can be observed. However, the W-4 connection has a smaller rotation angle, with much larger bending moments. The beam rotation takes place in relation to the bottom cleat, with the simultaneous resistance of the upper bracket, which is strongly deformed. The transverse force in these joints is transferred for the most part by the beam clamping to the bottom bracket and the bolts connecting the upper bracket to the column.

The Figures 7 and 8 show the maps of vertical displacements of the analyzed connections for the maximum values of bending moments.

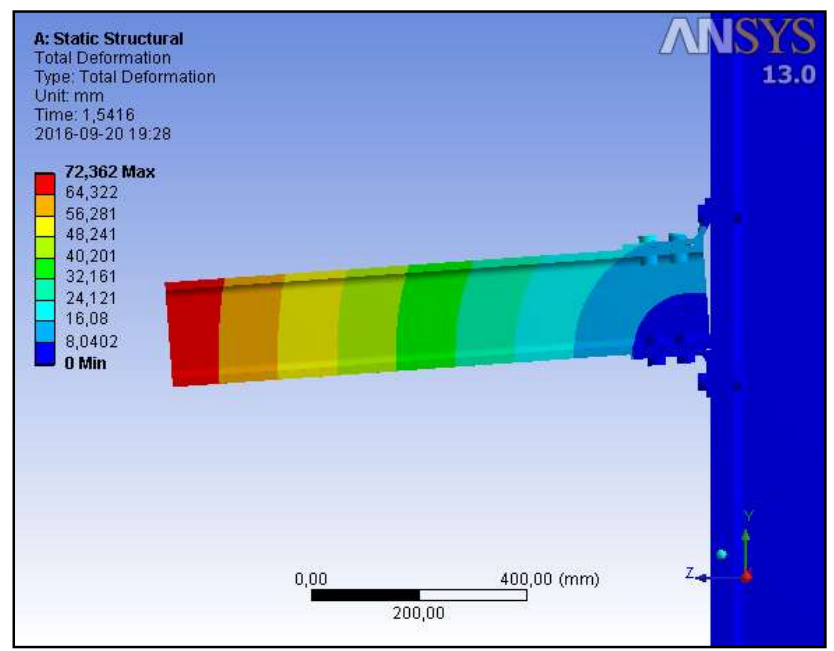

Fig. 7. The maps of vertical displacements for joint W-1. 


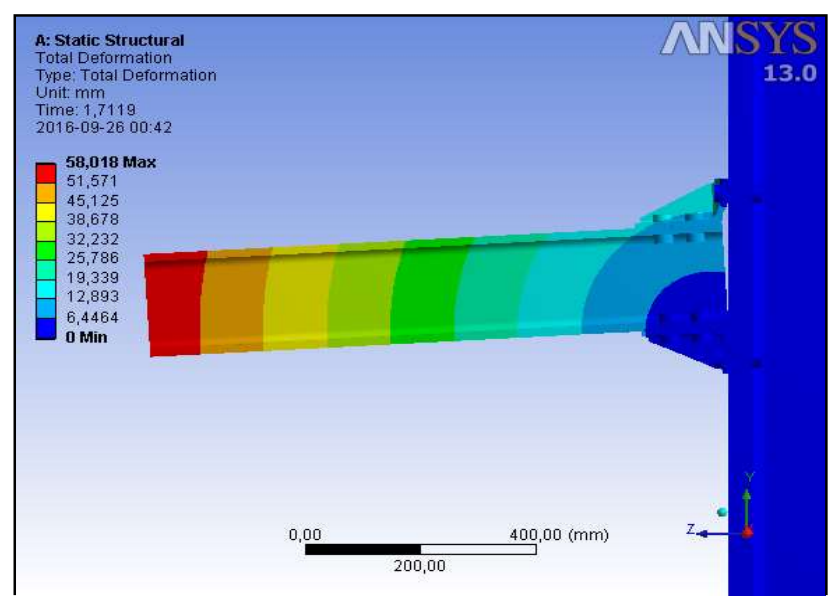

Fig. 8. The maps of vertical displacements for joint W-4.

It is worth noting that the beam and column do not deform too much. This is connected with the fact that the elements with the higher class of steel were accepted for the experimental study.

The results obtained after the calculations of connections with unstiffened and stiffened cleats in the ANSYS program were compared with the results of experimental studies carried out by Skejic and others [7,8]. Fig. 9 to 10 presents a comparison of moment - rotation curves obtained from experimental and numerical analyzes. Table 3. lists the bending resistance $\mathrm{M}_{\mathrm{j}, \mathrm{R}}$ and initial stiffnesses $\mathrm{S}_{\mathrm{j} \text {,ini }}$ of joints obtained from FEM and experiment analyzes.

\section{Connection W-1}

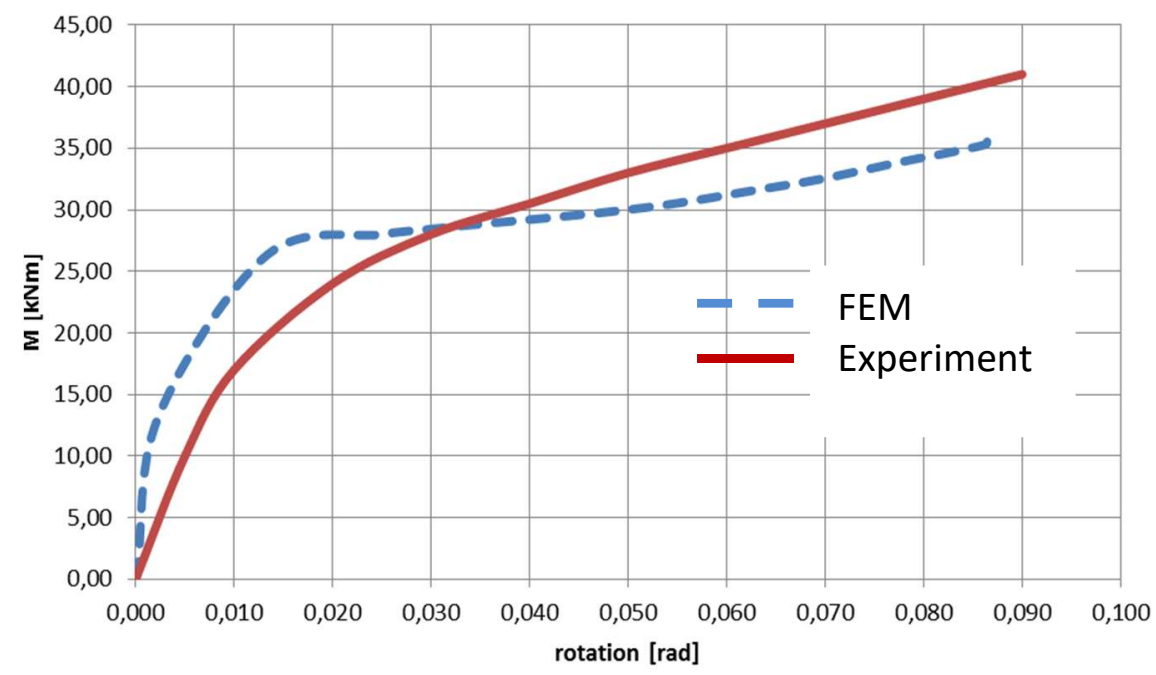

Fig. 9. Comparison of moment-rotation curves obtained from FEM analysis and experimental research for joint type W-1 


\section{Connection W-4}

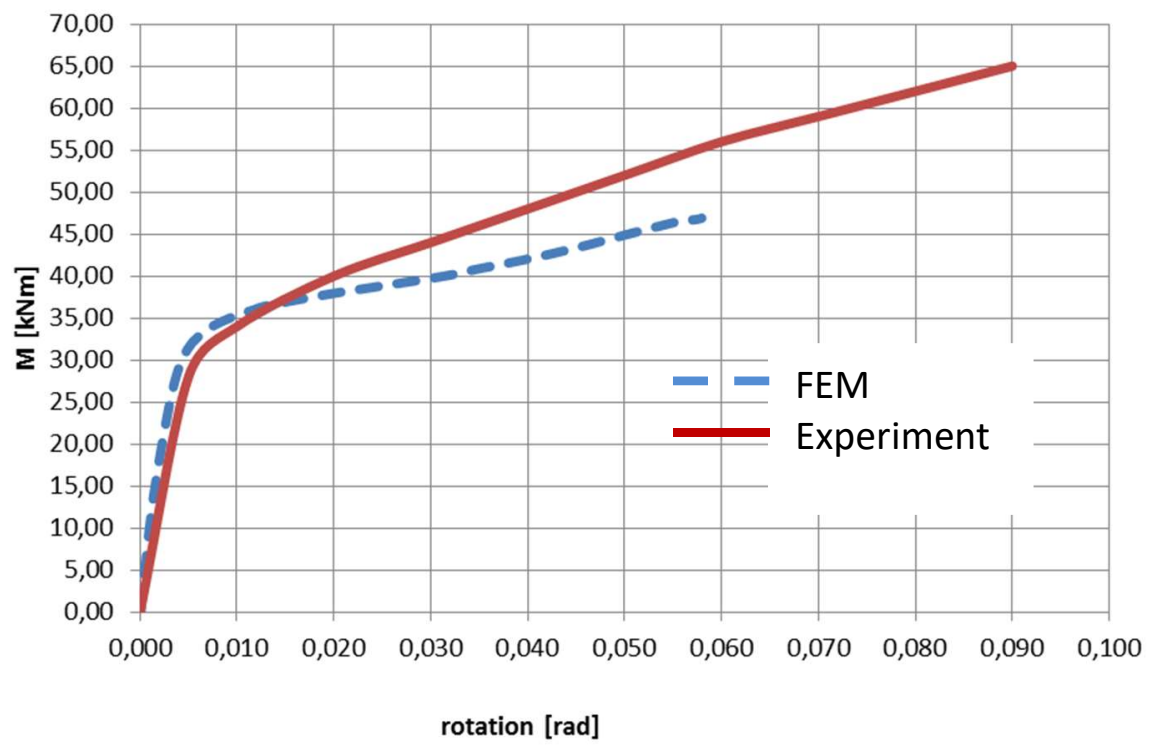

Fig. 10. Comparison of moment-rotation curves obtained from FEM analysis and experimental research for joint type $\mathrm{W}-4$

Table 3. Comparison the bending resistance $\mathrm{M}_{\mathrm{j}, \mathrm{R}}$ and initial stiffnesses $\mathrm{S}_{\mathrm{j}, \text { ini }}$ of joints obtained from FEM and experiment analyzes.

\begin{tabular}{|c|c|c|c|c|}
\hline \multirow{2}{*}{ Joint } & \multicolumn{2}{|c|}{ FEM analysis } & \multicolumn{2}{c|}{ Experimental researches } \\
\cline { 2 - 5 } & $\mathrm{M}_{\mathrm{j}, \mathrm{R}}[\mathrm{kNm}]$ & $\mathrm{S}_{\mathrm{j}, \text { ini }}[\mathrm{kNm} / \mathrm{rad}]$ & $\mathrm{M}_{\mathrm{j}, \mathrm{R}, \exp }[\mathrm{kNm}]$ & $\mathrm{S}_{\mathrm{j}, \text { ini }}[\mathrm{kNm} / \mathrm{rad}]$ \\
\hline $\mathrm{W}-1$ & 28,00 & 5600 & 27,77 & 3397 \\
\hline $\mathrm{W}-4$ & 35,01 & 7002 & 38,81 & 5432 \\
\hline
\end{tabular}

Analyzing the curves obtained from experimental and numerical analyzes, it can be stated that in the initial phase the numerical models show slightly higher stiffness. In the later phase, however, joints subjected to experimental research were characterized by lower deformability. Differences in the course of the curves can be caused by the failure to include in the FEM model executive imperfections resulting from the eccentric arrangement of bolts in the holes and different values of prestressing forces that can cause the bolt connections to slip for smaller values of bending moments. The values of bending resistance $\mathrm{M}_{\mathrm{j}, \mathrm{R}}$ and initial stiffnesses $\mathrm{S}_{\mathrm{j}, \text { ini }}$ obtained from numerical analyzes and experimental tests show a difference of less than $3 \%$.

\section{Conclusions}

The results presented herein focused on the comparison of moment resistance, stiffness of beam-to-column connections with unstiffened and stiffened flange cleats obtained from numerical analyzes and experimental tests. Analysis of the results showed good agreement between test results and FEM models.

For all joints the FE results lightly underestimates results achieved from experiments. Some differences in the initial value of stiffness and resistances indicate the need for further work on improving FEM models. The inclusion of dimensional deviations of the IPE and 
HEB sections, variability in the values of the prestressing forces of the bolts and the not centric positions of the bolts in the holes in the FEM model may contribute to increasing the degree of compliance of the results from experimental and numerical analyzes.

These results have shown that the FE method was a powerful tool to improve the knowledge about connections design. They could be used in advanced structural analysis of frames.

The paper was prepared at Bialystok University of Technology within a framework of the S/WBiIŚ/2/2017 project sponsored by Ministry of Science and Higher Education.

\section{References}

1. F. Bijlaard , J. of Constructional Steel Research , 62, pp.1060-1067 ( 2006)

2. J. Bródka J., A. Kozłowski, Stiffness and Strength of Semi-Rigid Connections (Bialystok University of Technology, Rzeszów University of Technology, Białystok-Rzeszów 1996) (in polish)

3. ENV 1993-1-8: Eurocode 3, Design of Steel Structures, Part 1-8 Design of Joints.

4. M. Gizejowski., W. Salah., W. Barcewicz, Archives of Civil Engineering, LVI, 1 (2010)

5. B. Stankiewicz, JCEEA, 30, No. 60 (2/13), pp.231-242, (2013)

6. A. Jabłońska-Krysiewicz ,E.Waśniewska Building structures in theory and practice, pp158-166 ( Pope John Paul II State School of Higher Education, Biała Podlaska 2013)

7. D. Skejić, D. Dujmovic, I. Lukacevic, Proc. EUROSTEEL 2011-6th European Conference on Steel and Composite Structures, Vol. A, pp. 309-314, Budapest, Hungary (2011)

8. D. Skejić, D. Berg, D. Dujmovic, Proc. EUROSTEEL 2014-7th European Conference on Steel and Composite Structures, Vol. 6, 62-012, Naples, Italy (2014)

9. ANSYS Manual. ANSYS 14.0. (On line help) 